\title{
CONDIÇÕES MICROBIOLÓGICAS DE CALDOS DE CANA COMERCIALIZADOS EM UMUARAMA (PR)
}

\section{MICROBIOLOGICAL CONDITIONS OF COMMERCIALIZED SUGAR CANE BROTH IN UMUARAMA CITY (PR)}

\author{
Eliezer Avila Gandra ${ }^{1}$; Amanda Felipe Reitembach ${ }^{2}$; Beatriz Cervejeira Bolanho ${ }^{3}$, Joise de Souza \\ Guimaraes ${ }^{4}$, Tatiane Kuka Valente Gandra ${ }^{5}$ \\ ${ }^{1}$ State University of Maringá - UEM - Umuarama - Brasil eagandra@uem.br \\ ${ }^{2}$ State University of Maringá - UEM - Umuarama - Brasil amandareitembach@hotmail.com \\ ${ }^{3}$ State University of Maringá - UEM - Umuarama - Brasil beatriz_bolanho@hotmail.com \\ ${ }^{4}$ State University of Maringá - UEM - Umuarama - Brasil joise_pussycats@hotmail.com \\ ${ }^{5}$ State University of Maringá - UEM - Umuarama - Brasil eagandra@uem.br
}

\begin{abstract}
Resumo
O caldo de cana, também conhecido popularmente como garapa, é uma bebida de grande aceitação pelo consumidor brasileiro, nos vendedores ambulantes normalmente é comercializada sem levar em consideração conceitos básicos de higiene. Este trabalho teve como objetivo avaliar as condições higiênico-sanitárias de caldos de cana comercializados na cidade de Umuarama(PR). Para isso, foram realizadas a enumeração de bactérias mesófilas aeróbias, coliformes totais e fecais, bolores e leveduras e Estafilococos coagulase positiva, em 24 amostras de caldos de cana provenientes de estabelecimentos comercializadores destes produtos em Umuarama(PR). Verificaram-se condições higiênico-sanitárias inadequadas das amostras analisadas, não sendo estas adequadas para o consumo.
\end{abstract}

Palavras-chave: higiene; qualidade sanitária; microrganismos patogênicos.

\section{Introdução}

Os alimentos e a água possuem um estreito relacionamento com a saúde do consumidor. Dependendo da sua composição, do seu manuseio e dos processos a que são submetidos podem tornar-se veículos de transmissão de diversas doenças, originadas principalmente por microrganismos e seus produtos extracelulares (UNGAR et al., 1992). Em função do risco à saúde pública que a presença de microrganismos representa em alimentos, estabeleceu-se em diversos países a obrigatoriedade de sua pesquisa e enumeração, como parte das ações de fiscalização sanitária de órgãos governamentais (SILVA et al., 1997; MATOS et al., 1995).

O Brasil é o maior produtor mundial de cana-de-açúcar apresentando até agosto de 2002 
uma produção de aproximadamente 360 mil toneladas/ano. Os cinco maiores estados produtores são São Paulo, Paraná, Alagoas, Minas Gerais e Pernambuco (AGRIANUAL, 2003).

Segundo LOPES et al. (2007) o caldo de cana é uma bebida extraída da cana-de-açúcar, planta que além de fornecer o suco é usada para produção de álcool e açúcar, o que explica a sua grande importância econômica, inclusive para o Brasil. O seu consumo como referesco é um costume antigo, que vem crescendo a cada ano, particularmente nas épocas mais quentes (LOPES et al., 2007; KITOKO et al., 2004).

O caldo de cana ou garapa é considerado popularmente um produto altamente nutritivo, de sabor agradável e de baixo custo. Este é comumente comercializado nas ruas por vendedores ambulantes, que possuem moendas para sua extração. A maioria desses vendedores não possui instalações compatíveis, assim como instrução adequada, que permita obtenção do produto em condições higiênico-sanitárias apropriadas (SOCCOL et al., 1990).

Esta bebida é naturalmente um meio favorável para o crescimento de microrganismos, mas a maior contaminação parece originar-se dos processos envolvidos em sua produção, através de equipamentos como: moendas, recipientes para coletas, jarras; além de condições errôneas de manipulação, de armazenamento, do ambiente e de pessoal (LOPES et al., 2007; KITOKO et al., 2004). Nesta situações os principais microrganimos que podem estar presentes são os do grupo coliformes (LOPES et al., 2007; RUSCHEL et al., 2001).

Segundo LOPES et al. (2007) esta comercialização torna-se preocupante, uma vez que o caldo de cana é consumido sem nenhum tipo de tratamento térmico que possa reduzir o número de microrganismos capazes de deteriorar o produto, ou de ocasionar doenças de origem alimentar.

A identificação de todos os microrganismos patogênicos capazes de estarem presentes em alimentos é cara e consome muito tempo. Por isso, utilizam-se determinados microrganismos ou grupos de microrganismos como indicadores das condições higiênico-sanitárias de produtos e processos. Entre esses, destacam-se a quantificação de coliformes totais e fecais, a contagem total de microrganismos mesófilos aeróbios, a enumeração de estafilococos coagulase positiva e a enumeração de bolores e leveduras (HAJDENWURCEL, 1998).

No noroeste do estado do Paraná praticamente não existem informações a respeito da qualidade microbiológica de estabelecimentos e de caldos de cana comercializados na região, sendo estas informações fundamentais para a garantia da qualidade dos produtos e da segurança alimentar dos consumidores.

Este trabalho teve como objetivo avaliar as condições higiênico-sanitárias de caldos de cana comercializados por ambulantes na cidade de Umuarama-PR. 


\section{Material e Métodos}

Os procedimentos de amostragem, assim como as determinações microbiológicas, foram realizadas de acordo com as recomendações de DOWNES \& ITO (2001) e SILVA et al. (1997).

Foram escolhidos 4 estabelecimentos ambulantes onde foram realizadas 12 coletas de três amostras de caldo de cana, que foram adquiridas na forma como são comercializadas, com um volume de $1000 \mathrm{~mL}$.

Imediatamente após cada coleta as amostras foram acondicionadas em uma caixa isotérmica contendo gelo e encaminhadas ao laboratório de Microbiologia de Alimentos do Centro de Tecnologia do Campus de Regional de Umuarama da Universidade Estadual de Maringá.

Para a enumeração de coliformes totais e fecais foi utilizada a técnica do Número Mais Provável (NMP). A análise presuntiva de coliformes foi realizada em Caldo Lauril Sulfato de Sódio $\left(\mathrm{LST}, \mathrm{MERCK}^{\circledR}\right)$, com incubação por 48 horas a $35^{\circ} \mathrm{C}$. Foi realizada também a enumeração de coliformes totais em Caldo Lactosado Bile Verde Brilhante, com incubação a $35^{\circ} \mathrm{C}$ por 24 a 48 horas. A enumeração de coliformes fecais foi feita em Caldo Escherichia coli, (EC, MERCK ${ }^{\circledR}$ ) com incubação a $45,5^{\circ} \mathrm{C}$ por 24 .

A quantificação de estafilococos coagulase positiva (ECP) foi realizada utilizando-se semeadura em Ágar Baird-Parker (MERCK ${ }^{\circledR}$ ), que foi incubado durante 48 horas a $37^{\circ} \mathrm{C}$, e 5 colônias características de cada placa foram submetidas à produção de coagulase livre.

A contagem de fungos foi realizada utilizando-se semeadura em Agar Batata Dextrose (BDA, MERCK ${ }^{\circledR}$ ) com incubação a $25^{\circ} \mathrm{C}$ por 5 dias.

A enumeração de bactérias mesófilas aeróbias foi realizada utilizando-se semeadura em Agar Para Contagem Total (Plate Count Agar -PCA, MERCK $^{\circledR}$ ) com incubação a $37^{\circ} \mathrm{C}$ por 24horas.

\section{Resultados e Discussão}

As amostras foram coletadas e analisadas em triplicata e os resultados foram expressos como médias destas três amostras. A Tabela 1 mostra os resultados obtidos das análises microbiológicas realizadas. 
Tabela 1 - Média dos valores encontrados nas contagens de unidades formadoras de colônia (UFC) de Estafilococos coagulase positiva e fungos filamentosos e técnica do Número Mais Provável (NMP) na enumeração de Coliformes Totais e Fecais no caldo de cana.

\begin{tabular}{lccccc}
\hline Amostra & $\begin{array}{c}\text { Mesófilos } \\
\text { aeróbios } \\
(\text { Log.UFC.mL }\end{array}$ & $\begin{array}{c}\text { Estafilococos } \\
\text { coagulase } \\
\text { positiva }\end{array}$ & $\begin{array}{c}\text { Fungos } \\
\left(\text { Log.UFC.mL }{ }^{-1}\right)\end{array}$ & $\begin{array}{c}\text { Coliformes totais } \\
\left(\text { Log.NMP.mL }{ }^{-1}\right)\end{array}$ & $\begin{array}{c}\text { Coliformes fecais } \\
\left(\text { Log.NMP.mL }^{-1}\right)\end{array}$ \\
\hline Coleta 1 & 6,56 & 2,48 & 5,25 & 1,04 & 1,81 \\
Coleta 2 & 5,54 & 6,81 & 5,34 & 3,04 & 3,38 \\
Coleta 3 & 5,24 & 6,97 & 6,04 & 3,38 & 3,38 \\
Coleta 4 & 5,06 & 4,42 & 5,91 & 3,38 & 3,87 \\
Coleta 5 & 6,91 & 5,35 & 6,04 & 3,38 & 3,04 \\
Coleta 6 & 5,63 & 4,15 & 5,89 & 3,38 & 3,38 \\
Coleta 7 & 4,96 & 2,90 & 5,43 & 3,38 & 3,38 \\
Coleta 8 & 6,25 & 3,73 & 4,91 & 3,38 & 0,60 \\
Coleta 9 & 5,39 & 4,02 & 5,23 & 2,66 & 0,95 \\
Coleta 10 & 4,89 & 5,69 & 5,43 & 2,38 & 2,38 \\
Coleta 11 & 5,47 & 5,27 & 5,86 & 2,38 & 2,38 \\
Coleta 12 & 5,20 & 3,99 & 5,15 & 2,66 & \\
\hline
\end{tabular}

Os resultados das contagens de bactérias mesófilas aeróbias variaram entre os valores de 4,89 Log.UFC.mL ${ }^{-1}$ e 6,91 Log.UFC.mL ${ }^{-1}$. A legislação brasileira em vigor (Resolução RDC nº 12 de 02 de janeiro de 2001, do Ministério da Saúde) não estabelece padrões para a contagem de bactérias mesófilas totais e fungos para caldo de cana. No entanto, a pesquisa de bactérias mesófilas aeróbias tendo sido usada como indicador da qualidade higiênica dos alimentos.

Segundo PRATI (2004) quando a contagem padrão em placas de bactérias mesófilas aeróbias está acima de 6Log.UFC.mL ${ }^{-1}$ o produto alimentício pode apresentar alterações nas suas características sensoriais, ou seja, pode apresentar deterioração. Em nosso estudo em três coletas (1, 2 e 8) foram verificadas enumerações acima desta margem, evidenciando o estado deteriorativo que estas amostras poderiam estar. Além disso, para FRANCO \& LANDGRAF, (2002) presença desses microorganismos em grande número, como a apresentada neste trabalho, indica matéria-prima excessivamente contaminada, limpeza e desinfecção de superfícies inadequadas, higiene insuficiente na produção e condições impróprias de tempo e temperatura durante a conservação dos alimentos.

A contagem de Bolores e Leveduras apresentou carga microbiana na ordem de 4,91 a 6,04 Log.UFC. $\mathrm{mL}^{-1}$. A pesquisa de bolores e leveduras, que era exigida pela Portaria $\mathrm{n}^{\circ} 451$ de 19 de setembro de 1997 do Ministério da Saúde (Brasil, 1997) foi revogada pela Resolução RDC $\mathrm{n}^{\circ} 12$ de 02 de janeiro de 2001, do Ministério da Saúde (Brasil, 2001), ainda que estes estejam comumente presentes em amostras de caldo de cana (LOPES et al., 2007; KITOKO et al., 2004). Os bolores e leveduras são contaminantes comuns em sucos de frutas e caldo de cana e representam uma grande preocupação, pois se sabe do poder deteriorativo destes microrganismos e da capacidade de algumas espécies de produzirem micotoxinas (FRANCO \& LANDGRAF, 2002). 
Nas amostras analisadas detectou-se a presença de Estafilococos coagulase positiva (ECP), em quantidades que variaram de 2,48 Log.UFC.mL ${ }^{-1}$ a 6,97 Log.UFC.mL ${ }^{-1}$. Os valores encontrados denotam uma situação preocupante, pois, apesar de não existirem padrões para este grupo bacteriano em caldo de cana na legislação brasileira, sabe-se que os ECP são produtores de enterotoxinas termoestáveis em alimentos (SILVA \& GANDRA, 2004; FRANCO \& LANDGRAF, 2002).

Os resultados encontrados na enumeração de ECP explicitam novamente a falta de práticas higiênicas na elaboração do caldo de cana pelo manipulador. Uma medida simples que poderia ser implementada seria os manipuladores fazerem o uso de mascaras faciais, pois segundo KONEMAN et al. (2001), as vias aéreas superiores são o principal reservatório de ECP em humanos, sendo o ponto a partir do qual essas bactérias se disseminam no ambiente.

Todas as amostras analisadas apresentaram coliformes totais e fecais. Quanto a analise destes últimos, 58,3\% das amostras apresentaram contagens superiores 2 Log.NMP.mL ${ }^{-1}\left(10^{2}\right.$ NMP.mL ${ }^{-1}$ ) que é o valor máximo permitido pela Resolução RDC nº 12 de 02 de janeiro de 2001, do Ministério da Saúde (Brasil, 2001) estando estas amostras impróprias para o consumo.

Em acordo com estes resultados KITOKO et al. (2004) verificaram a presença de coliformes fecais em todas as amostras analisadas em um estudo realizado no comércio ambulante de Vitória ES e SOARES (1999), que verificou em 100\% das amostras de caldo de cana coletadas em Belém PA contagens coliformes totais e fecais superiores a 2 Log NMP.mL ${ }^{-1}$.

Já LOPES et al. (2007) e RUSCHEL et al.(2001) verificaram resultados contrastantes com os encontrados neste estudo. Os primeiros verificaram apenas uma amostra entre trinta analisadas com contagem de coliformes fecais superior a 2 Log NMP.mL ${ }^{-1}$ em estudo realizado com amostras de caldo de cana coletadas nas ruas de Curitiba-PR. O segundos verificaram contaminação por coliformes fecais acima de 2 Log NMP.mL ${ }^{-1}$ em apenas 5,76\% de 52 amostras analisadas de sucos in natura comercializados nas ruas de Porto Alegre-RS. Os primeiros autores atribuíram este baixo índice de contaminação com a baixa temperatura ambiental no período de coleta, que ocorreu no inverno, ao fato do produto não ter sido coletado com gelo, pois este pode constituir uma fonte de contaminação e a extração do caldo de cana ter sido realizada na hora do consumo.

A diferença de resultados entre este trabalho e os desenvolvidos por LOPES et al. (2007) e RUSCHEL et al.(2001) pode estar relacionada com as condições de coleta, pois, neste estudo, a média de temperatura estava acima de $26^{\circ} \mathrm{C}$ e várias amostras que foram coletadas estavam prontas para o consumo e armazenadas no estabelecimento em recipientes com gelo.

A presença expressiva de coliformes, principalmente de fecais (coliformes a $45^{\circ} \mathrm{C}$ ), nas amostras de caldo de cana (Tabela 1), denota um risco potencial a saúde dos consumidores, já que este grupo microbiano está presente na flora intestinal de humanos e animais sendo um indicador de 
contaminação fecal (JAY, 2005). Sua presença em alimentos evidencia falha grave no procedimento higiênico-sanitário do estabelecimento produtor e/ou comercializador, representando risco aos consumidores, já que alguns sorogrupos da espécie Escherichia coli (principal espécie do grupo dos coliformes fecais) apresentam potencial patogênico por produzirem toxinas e/ou invadirem as células entéricas (LOPES et al., 2007; TRABULSI et al., 1999).

Estes resultados também se relacionam, provavelmente, com contaminações cruzadas decorrentes da inadequação higiênica e sanitária dos manipuladores, água e utensílios utilizados pelos ambulantes de Umuarama, evidenciando contato do caldo de cana com material fecal, direta ou indiretamente, sugerindo a possível presença de outros enteropatógenos, incluindo outras bactérias e vírus enteropatogênicos.

Segundo PRATI (2004) e SOARES (1999) a grande carga microbiana presente em caldos de cana pode ser atribuída a uma série de falhas na obtenção do produto como: a má manipulação e estocagem, do ponto de vista higiênico, dos colmos; duvidosa potabilidade da água usada na limpeza da cana, dos utensílios e da moenda; acondicionamento do caldo por longos períodos em recipientes de limpeza duvidosa, os quais são, na maioria das vezes, tampados com pedaços do próprio colmo da cana.

LOPES et al.(2007) relatam que entre os comerciantes são adotados diversos procedimentos inadequados do ponto de vista higiênico, como: a manipulação de dinheiro; uso de panos sujos para limpar as mãos, roupas e unhas; além de produtos encontrados prontos para a venda sem refrigeração adequada, medidas estas que propiciam a contaminação por microrganismos deteriorantes e/ou patogênicos.

Estes não parecem ser problemas atuais e nem limitados à região de Umuarama, e sim de espectro geral, pois vários trabalhos vêm sendo desenvolvidos a mais de uma década e em regiões diferentes, encontrando condições similares.

Como exemplo podemos citar o trabalho desenvolvido por SOCCOL et al. (1990) em Curitiba-PR, entre 1988 e 1989, que verificaram que 78\% de 50 amostras de caldo de cana estavam em desacordo com as especificações legais que vigoravam na época.

Em função disso, fica clara a exigência de um controle maior relativo ao processo produtivo de caldo de cana, evidenciando a necessidade de implantação, nestes estabelecimentos, de normas de procedimento fundamentadas em programas de boas práticas de fabricação, para que estes produtos deixem de representar um risco para a saúde do consumidor.

Como sugestão, objetivando melhorar a qualidade do caldo de cana comercializado, evitando conseqüências danosas tanto à saúde do consumidor quanto à durabilidade do produto, algumas medidas deveriam ser implementadas como a sanificação de equipamentos e dos colmos 
da cana-de-açúcar, a implantação de boas práticas de fabricação, a aplicação de treinamento aos vendedores ambulantes e fiscalização mais efetiva dos estabelecimentos.

\title{
4. Conclusão
}

Verificou-se condições higiênico-sanitárias inadequadas nas amostras de caldo de cana obtidas de vendedores ambulantes da cidade de Umuarama (PR). Em função da presença de coliformes fecais em valores acima do permitido pela legislação brasileira, 58,3 \% das amostras apresentaram-se inadequadas para o consumo.

\begin{abstract}
The sugar cane broth, also known popularly as garapa, is a drink of great acceptance for the Brazilian consumer, and in the ambulant salesmen, normally it is commercialized without taking in consideration basic concepts of hygiene. This work had as objective to evaluate the hygienically sanitary conditions of commercialized sugar cane broth in the Umuarama city (PR). For this, they had been carried through the enumeration of mesophilic aerobic bacteria, total and faecal coliforms, fungi and Staphylococcus coagulase positive, in 24 samples of broth sugar cane proceeding from establishments of these products in Umuarama (PR). It was verified inadequate hygienically sanitary conditions of the analyzed samples, not being these adjusting for the consumption.
\end{abstract}

Key-words: hygiene; sanitary quality; pathogenic microorganisms.

\section{Referências}

AGRIANUAL. Anuário da Agricultura Brasileira. São Paulo: Argos/FNP Consultoria e comércio, 2003.

BRASIL. Portaria n 451, de 19 de setembro de 1997. Regulamento técnico. Princípios gerais para o abastecimento de critérios e padrões microbiológicos para alimentos. Diário Oficial da República Federativa do Brasil, Brasil, $n^{\circ} 182$, p. 21005-21011, 22 set. 1997, seção I.

BRASIL. Resolução-RDC n 12, de 02 de Janeiro de 2001. Regulamento técnico sobre padrões microbiológicos para alimentos. Diário Oficial da Republica Federativa do Brasil, Brasil, n 7-E, p. 46-53, 10 Jan. 2001, seção I.

DOWNES, F. P., ITO, H. Compendium of methods for the microbiological examination of foods. 4 . ed. Washington: American Public Health Association (APHA), 2001. 676p.

FRANCO, B. D. G. M. \& LANDGRAF, M. Microbilogia dos Alimentos. 2 ed. São Paulo: Editora Atheneu, 2002. $184 \mathrm{p}$.

HAJDENWURCEL, J. R. Atlas de microbiologia de alimentos. São Paulo: Fonte Comunicações e Editora, v. 1, 1998. 98p.

KITOKO, P. M.; OLIVEIRA, A. C.; SILVA, M. L. Avaliação microbiológica do caldo de cana comercializado em Vitória, Espírito Santo, Brasil. Higiene Alimentar, n.119, v.18, p.73-76, 2004.

KONEMAM, E. W., ALLEN, S. D., JANDA, W. M., SCHRECKENBERGER, P. C., WINN JR., W. C. Diagnóstico Microbiológico. São Paulo: Medsi Editora Médica e Científica Ltda., 2001. 1466p.

LOPES, G.; CRESTO, R.; CARRARO, C. N. M. Análise microbiológica de caldos de cana comercializados nas ruas de Curitiba, PR. Higiene Alimentar, n.147, v.20, p.40-44, 2007.

MATOS, J. E. S.; HARMON, R. J.; LANGLOIS, B. E. Lecithinase reaction of Staphylococcus aureus strains of different origin on baird parker medium. Letters in Applied Microb., v.21, p.334-335. 1995. 
PRATI, P. Desenvolvimento de processo de estabilização de caldo de cana adicionado de sucos de frutas ácidas. 2004. Tese (Doutorado em Tecnologia de Alimentos) - Faculdade de Engenharia de Alimentos, Universidade Estadual de Campinas, Campinas, 2004.

SILVA, N.; JUnQUEIRA, V. C. A.; SILVEIRA, N. F. A. Manual de Métodos de Análise Microbiológica de Alimentos. São Paulo: Livraria Varela, 1997. 296p.

SILVA, W. P. \& GANDRA, E. A. Estafilococos coagulase positiva: patógenos de importância em alimentos. Higiene Alimentar, n.122, v.18, p. 32-39, 2004.

SOARES, M. S. Estudo comparativo de métodos de enumeração de coliformes em alimentos. 1999. 52p. Trabalho de Conclusão de Curso (Especialização em Tecnologia de Alimentos) - Universidade Federal do Pará, Belém, 1999.

SOCCOL, C.R.; SCHWAB, A.; KATAOKA, C. E. Avaliação microbiológica do caldo de cana (garapa) na cidade de Curitiba. Boletim do Centro de Pesquisa e Processamento de Alimentos, n.2, v.8, p.116-125, 1990.

RUSCHEL, C. K; CARVALHO, H.H.; SOUZA, RB de; TONDO, E.C. Qualidade microbiológica e físico química de sucos de laranja comercializados nas vias públicas de Porto Alegre/RS. Ciência Tecnologia Alimentos, n.1, v.21, p.9497, 2001.

TRABULSI, R T.; ALERTHUM, F.; CANDEIAS, J.N.; GOMPETZ, O. F. Microbiologia. 3. ed. São Paulo: Atheneu, 1999. $586 \mathrm{p}$.

UNGAR, M. L.; GERMANO, M. I. S; GERMANO, P. M. L. Riscos e conseqüências da manipulação de alimentos para a saúde pública. Higiene Alimentar, n.21, v.6, p.14-16, 1992.

\section{Inserir dados completos de todos os autores:}

Nome completo: Eliezer Avila Gandra

Filiação institucional: Universidade Estadual de Maringá

Departamento: Campus Regional de Umuarama, Centro de Tecnologia

Função ou cargo ocupado: Professor Adjunto

Endereço completo para correspondência: Laboratório de Microbiologia de Alimentos, Centro de Tecnologia (CTC), Campus Regional de Umuarama (CAU), Universidade Estadual de Maringá (UEM), Rodovia PR 489, №1400, Umuarama, PR. CEP. 87508-210

Telefones para contato: (44) 3621-9336 e (44) 8402-1077

e-mail:eagandra@uem.br

Nome completo: Amanda Felipe Reitembach

Filiação institucional: Universidade Estadual de Maringá

Departamento: Campus Regional de Umuarama, Centro de Tecnologia.

Função ou cargo ocupado: Aluna do curso de Tecnologia em Alimentos, bolsista do Programa de Iniciação Científica - PIC/UEM.

Endereço completo para correspondência: Laboratório de Microbiologia de Alimentos, Centro de Tecnologia (CTC), Campus Regional de Umuarama (CAU), Universidade Estadual de Maringá (UEM), Rodovia PR 489, №1400, Umuarama, PR. CEP. 87508-210 
Telefones para contato: (44) 3621-9336 e (44) 8402-1077

e-mail: amandareitembach@hotmail.com

Nome completo: Beatriz Cervejeira Bolanho

Filiação institucional: Universidade Estadual de Maringá

Departamento: Campus Regional de Umuarama, Centro de Tecnologia.

Função ou cargo ocupado: Aluna do curso de Tecnologia em Alimentos, bolsista do Programa de Institucional de Bolsas de Iniciação Científica - PIBIC/CNPq/ Fundação Araucária/UEM.

Endereço completo para correspondência: Laboratório de Microbiologia de Alimentos, Centro de Tecnologia (CTC), Campus Regional de Umuarama (CAU), Universidade Estadual de Maringá (UEM), Rodovia PR 489, №1400, Umuarama, PR. CEP. 87508-210

Telefones para contato: (44) 3621-9336 e (44) 8402-1077

e-mail: beatriz_bolanho@hotmail.com

Nome completo: Joise de Souza Guimaraes

Filiação institucional: Universidade Estadual de Maringá

Departamento: Campus Regional de Umuarama, Centro de Tecnologia.

Função ou cargo ocupado: Aluna do curso de Tecnologia em Alimentos, bolsista do Programa de Iniciação Científica - PIC/UEM.

Endereço completo para correspondência: Laboratório de Microbiologia de Alimentos, Centro de Tecnologia (CTC), Campus Regional de Umuarama (CAU), Universidade Estadual de Maringá (UEM), Rodovia PR 489, Nº1400, Umuarama, PR. CEP. 87508-210

Telefones para contato: (44) 3621-9336 e (44) 8402-1077

e-mail: joise_pussycats@hotmail.com

Nome completo: Eliezer Avila Gandra

Filiação institucional: Universidade Estadual de Maringá

Departamento: Campus Regional de Umuarama, Centro de Tecnologia

Função ou cargo ocupado: Professora Colaboradora

Endereço completo para correspondência: Laboratório de Microbiologia de Alimentos, Centro de Tecnologia (CTC), Campus Regional de Umuarama (CAU), Universidade Estadual de Maringá (UEM), Rodovia PR 489, №1400, Umuarama, PR. CEP. 87508-210

Telefones para contato: (44) 3621-9336 e (44) 8402-1077

e-mail:eagandra@uem.br 